Family Medicine and Community Health

\title{
Utilisation of smoking cessation aids among South African adult smokers: findings from a national survey of 18208 South African adults
}

\author{
Israel Agaku, ${ }^{1,2}$ Catherine Egbe, ${ }^{3,4}$ Olalekan Ayo-Yusuf ${ }^{3}$
}

To cite: Agaku I, Egbe C, AyoYusuf 0 . Utilisation of smoking cessation aids among South African adult smokers: findings from a national survey of 18208 South African adults. Fam Med Com Health 2021;9:e000637. doi:10.1136/fmch-2020-000637

- Additional material is published online only. To view, please visit the journal online (http://dx.doi.org/10.1136/fmch2020-000637).

Check for updates

(C) Author(s) (or their employer(s)) 2020. Re-use permitted under CC BY-NC. No commercial re-use. See rights and permissions. Published by BMJ.

${ }^{1}$ School of Health System and Public Health, University of Pretoria, Pretoria, Gauteng, South Africa

${ }^{2}$ Oral Health Policy and Epidemiology, Harvard School of Dental Medicine, Boston,

Massachusetts, USA

${ }^{3}$ Africa Center for Tobacco Industry Monitoring and Policy Research, Sefako Makgatho Health Sciences University, Pretoria, Gauteng, South Africa ${ }^{4}$ South African Medical Research Council, Tygerberg, South Africa

Correspondence to

Dr Israel Agaku;

u16218435@tuks.co.za

\section{ABSTRACT}

Objective To examine the use of different cessation aids among current South African smokers who have ever tried to quit smoking.

Design Cross-sectional design.

Setting South Africa has progressively passed several policies over the past few decades to encourage smoking cessation. Data on cessation behaviours are needed to inform policymaking. We investigated utilisation of evidence-based cessation aids and e-cigarettes among current combustible smokers. Current tobacco use, past quit attempts and use of evidence-based cessation aids (counselling, nicotine replacement therapy or prescription medication) were self-reported. Data were weighted and analysed using descriptive and multivariable approaches $(p<0.05)$.

Participants Online participants were recruited from the national consumer database for News24South Africa's largest digital publisher. Of the 18208 participants aged 18 years or older, there were 5657 current smokers of any combustible tobacco product (cigarettes, cigars, pipes or roll-your-own cigarettes), including 4309 who had ever attempted to quit during their lifetime.

Results Current combustible tobacco smoking prevalence was $22.4 \%$ ( $95 \% \mathrm{Cl}: 21.2 \%$ to $23.5 \%$ ), and $98.7 \%$ of all current smokers of any combustible tobacco were current cigarette smokers. Awareness of cessation aids was as follows among current combustible tobacco smokers: smoking cessation counselling programmes, $50.8 \%$ (95\% Cl: $48.1 \%$ to $53.6 \%)$; nicotine replacement therapy, $92.1 \%$ (95\% Cl: $90.5 \%$ to $93.6 \%$ ); prescription cessation medication, $68.2 \%$ (95\% Cl: $65.2 \%$ to $70.6 \%$ ). Awareness of cessation aids was lowest among Black Africans, men, and persons with little or no income. Of all current combustible tobacco smokers, $74.6 \%$ (95\% Cl: $72.2 \%$ to $76.7 \%)$ had ever attempted to quit and $42.8 \%$ (95\% Cl: $40.0 \%$ to $45.4 \%$ ) of these quit attempters had ever used any cessation aid. Among current combustible smokers who attempted to quit in the past, ever e-cigarette users were more likely than never e-cigarette users to have ever used any cessation aid $(50.6 \%$ vs $35.9 \%, p<0.05)$. Of current combustible smokers intending to quit, $66.7 \%$ (95\% $\mathrm{Cl}: 64.2 \%$ to $68.9 \%$ ) indicated interest in using a cessation aid for future quitting. By specific aids,

\section{Key points}

Question

What types of cessation aids are being used among South African smokers to quit smoking?

\section{Findings}

- Current combustible tobacco smoking prevalence was $22.4 \%$. Awareness of cessation aids was as follows among current combustible smokers: smoking cessation programmes, $50.8 \%$; nicotine replacement therapy, 92.1\%; prescription cessation medication, $68.2 \%$. Awareness of cessation aids was lowest among Black Africans, men and persons with little or no income. Of all current combustible smokers, $74.6 \%$ had ever attempted to quit and $42.8 \%$ of these quit attempters had ever used any cessation aid. Among past quit attempters, ever e-cigarette users were more likely than never e-cigarette users to have ever used any cessation aid $(50.6 \%$ vs $35.9 \%, p<0.05)$. Of current combustible smokers intending to quit, $66.7 \%$ indicated interest in using a cessation aid for future quitting and only $33.3 \%$ wanted to quit cold turkey.

\section{Meaning}

- Only two in five past quit attempters had ever used a cessation aid, and this was higher among smokers who also used e-cigarettes than non-users, suggesting that any potential cessation benefits seen with e-cigarettes may be partly attributable to use of other aids.

$24.7 \%$ (95\% Cl: $21.3 \%$ to $28.1 \%$ ) of those planning to use any cessation aid were interested in getting help from a pharmacist, $44.6 \%$ (95\% Cl: $40.9 \%$ to $48.4 \%)$ from a doctor, $49.8 \%$ (95\% Cl: $46.0 \%$ to $53.6 \%$ ) from someone who had successfully quit, $30.0 \%(95 \% \mathrm{Cl}$ : $26.7 \%$ to $33.4 \%$ ) from a family member and $26.5 \%$ (95\% Cl: $23.0 \%$ to $30.0 \%$ ) from web resources.

Conclusion Only two in five past quit attempters had ever used counselling/pharmacotherapy. Any putative benefits of e-cigarettes on cessation may be partly attributable to pharmacotherapy/counselling given concurrent use patterns among past quit attempters using e-cigarettes. Comprehensive tobacco control 
and prevention strategies can help reduce aggregate tobacco consumption.

\section{INTRODUCTION}

During 2016, 21.5\% of South African adults smoked cigarettes. ${ }^{1}$ About $20 \%$ of deaths from pulmonary tuberculosis, and $8 \%$ of all deaths in South Africa are attributable to smoking. ${ }^{23}$ Several of the 10 leading causes of death in South Africa (eg, tuberculosis, pneumonia, heart disease, cerebrovascular disease, diabetes, hypertensive disease and chronic respiratory disease) are caused, exacerbated or associated with smoking. ${ }^{2}{ }^{5}$ Quitting smoking reduces the risk for smoking-related morbidity and mortality. While several cessation aids exist in South Africa, including the national quit-line (011 720 3145) and clinical resources (eg, pharmacotherapy and cessation counselling), the limited evidence to date reveals gaps in access and utilisation. ${ }^{67}$ Only $29.3 \%$ of South African smokers received healthcare professional advice to quit smoking during 2012. ${ }^{8}$ South Africa has progressively passed several policies over the past few decades to encourage smoking cessation. ${ }^{9-12}$ However, smoking cessation medications are not included in the essential medicines list for South Africa, and therefore, all associated costs for these medications must be paid out-ofpocket, a challenge for individuals of low socioeconomic position. ${ }^{13-15}$ Data are needed, not only on what smokers are using to quit smoking (ie, cessation aids), but also why smokers are trying to quit (ie, cessation triggers), as this could inform public health policies, programmes and practice.

The Health Belief Model provides an appropriate framework through which to examine and address smoking cessation interventions in South Africa. ${ }^{16}$ Applied to smoking cessation, this psychosocial model suggests that smokers will attempt to quit if they perceive themselves to be susceptible to smoking-attributable morbidity or mortality (eg, because of an underlying health condition or a health scare), and believe that the benefits of smoking cessation (health and/or economic) outweigh any perceived downsides (eg, diminished smoking sensory experience). Other components of the model have some implications for clinical and public health practitioners. For example, cues to action may include advice or assistance from a healthcare provider to motivate quitting. Such cues may also include comprehensive smoke-free policies and other population-level educational interventions that have been demonstrated in previous research to be associated with quitting behaviour. ${ }^{4}$ Perceived selfefficacy (belief in being able to quit successfully) is a very important component of the model as it offers insights into the smoker's current stage of change (precontemplation, contemplation, action, maintenance),${ }^{17}$ and may also have implications for usage of evidence-based cessation aids. ${ }^{18}$ For example, smokers who are not confident of their ability to quit successfully cold turkey may be more inclined to use smoking cessation aids as part of their quit attempt.

To better understand these issues within the South African context, this study analysed a large sample of current combustible tobacco smokers to assess use of cessation aids as well as demographic and psychographic correlates of cessation behaviour. Specific research questions were as follows: (1) What percentage of current combustible smokers have ever attempted to quit during their lifetime, and what types of cessation aids have they ever used? (2) What are barriers to smoking cessation among current combustible smokers who have never attempted to quit during their lifetime? A better understanding of these issues is important for comprehensive tobacco prevention and control activities in South Africa.

\section{METHODS}

\section{Data sources}

This was a cross-sectional, web-based survey of South African adults aged $\geq 18$ years conducted in July 2018 $(\mathrm{n}=18$ 208). Online participants were recruited from the national consumer database for News24-South Africa's largest digital publisher. As an incentive, consenting participants were eligible for a raffle draw prize of R5000 for completing the survey. Survey completion rates among eligible individuals who clicked on the email invitations was $75.3 \%$ (20 383/27 087, online supplemental figure 1). For our main analyses, the denominator was current smokers of any combustible tobacco product (ie, cigarettes, cigars, pipes or roll-your-own (RYO) cigarettes; $\mathrm{n}=5657$ ), who indicated they had not quit smoking at the time of the survey and smoked every day, some days, or rarely.

\section{Measures}

\section{Current combustible tobacco use}

Current combustible tobacco smokers $(n=5657)$ were defined as individuals who self-identified as being a regular user of any 'smoke or smokeless' product in general and reported using at least one combustible tobacco product at the time of the survey at any frequency (cigarettes, pipes, cigars and RYO tobacco). Those who answered 'used but stopped' to all of the combustible tobacco products assessed were excluded from the analyses.

Quitting intentions, behaviours, attitudes and cessation aids Smokers were classified as having no quit intention if they indicated: 'I've never tried to quit and don't want to' or 'I've tried before and failed, so why try again?' A past quit attempt was defined as a report by a smoker that they had made $\geq$ one quit attempt in their lifetime, regardless of success. Participants were classified as having successfully quit within the past year if they answered 'less than a month'; '1-6 months' or '6-12 months' to the question 'How long ago did you quit smoking?' Triggers for past quit attempts (among those who had ever tried to quit) 
as well as potential/perceived triggers for future quit attempts (among those who had never tried to quit) were also assessed.

We were interested in past use of evidence-based cessation aids (among those who had ever tried to quit) as well as planned use (among those with quit intentions). The full list of response options for each assessed item in terms of ever or current use status was "never heard of'; 'heard of, never used', 'use rarely/once off', 'use regularly' and 'used but stopped'. Usage, both ever ('use rarely/once off', 'use regularly' and 'used but stopped') and current ('use rarely/once off', 'use regularly'), was determined for the following cessation aids: (1) 'nicotine sprays' (eg, Quit); (2) 'nicotine gums' (eg, Nicorette); (3) 'pharmaceutical medication to stop smoking' (eg, Zyban, Champix); (4) 'smoking cessation programmes' (eg, SmokEnders, Allan Carr) (ie, cessation counselling programmes). Responses (1) or (2) were classified as nicotine replacement therapy (NRT). Responses (1), (2) or (3) were classified as any medication. Any of aids (1) through (4) was classified as having used any cessation aid. Smokers were classified as being aware of each of the above interventions if they had ever used it, or "heard of, (but) never used'. Planned use of cessation aids was ascertained for 'if/when (respondents) were ready to quit smoking; those answering 'I would rely on willpower' were classified as intending to quit cold turkey. Inveterate smokers were defined as current combustible smokers who had never made a quit attempt in their lifetime and had no intention to quit smoking.

\section{Sociodemographic and other characteristics}

These included race/ethnicity, gender, age, monthly personal income and self-rated health status.

\section{Analyses}

Calibration weights were developed using raking (iterative proportional fitting); population marginal distributions on the weighting variables were derived from the 2017 South African census projections (ie, reference population). Weighting was done using three adjustment variables: age, gender and race/ethnicity. Percentages and bootstrapped CIs were calculated for descriptive analyses; non-overlap of CIs was used, along with $\mathrm{X}^{2}$ tests, to determine whether prevalence estimates were significantly different from each other. Bootstrapping, a non-parametric approach, was used to compute CIs for prevalence estimates in the absence of non-probabilitybased sampling. Because of the large amount of descriptive data, we minimised the number of statistical subgroup comparisons to avoid type I statistical error. Instead, inferences regarding global differences were largely made conservatively based on presence or absence of overlap of the computed $95 \%$ CIs. Logistic regression analyses were used to explore correlates of reporting specific quit triggers among those who had made a past quit attempt; predictor variables assessed were race/ethnicity, gender, age, monthly personal income, self-rated health status and age at smoking initiation. We also modelled quit attempt as a function of reported reason for smoking behaviour, controlling for aforementioned independent variables. Statistical significance was assessed at $\mathrm{p}<0.05$. All statistical analyses were performed with R V.3.6.1.

\section{SENSITIVITY ANALYSES}

The inherent limitations of the web survey in terms of potential measurement and selection biases led us to conduct sensitivity analyses to determine how certain key measures from the weighted analyses compared with those from a nationally representative household survey of South African adults-the 2017 South African Social Attitudes Surveys (SASAS). We compared the following indicators that were present in both surveys: (1) prevalence of current any tobacco use and of current cigarette smoking; (2) percentage of smokers who made a quit attempt (lifetime quit attempt assessed in web survey vs past year quit attempt in SASAS) and (3) percentage of those who made a quit attempt that used any cessation aid.

\section{RESULTS}

Weighted distributions among all respondents overall revealed that most individuals $(68.8 \%)$ were Black Africans and women $(52.2 \%)$. Other demographic characteristics are available in table 1 . Overall, $72.0 \%$ of the population reported ever use prevalence of at least one tobacco product. Current use prevalence was as follows: any tobacco product $(23.2 \%)$; any combustible tobacco product $(22.4 \%)$ and cigarettes $(22.1 \%)$; (table 1 ). Overall, $98.7 \%$ of current smokers of any combustible tobacco were current cigarette smokers.

Significant differences in tobacco use prevalence were seen among all demographic groups assessed, as evidenced from non-overlap of CIs in table 1. Awareness of cessation aids was as follows among current combustible smokers: smoking cessation programmes, $50.8 \%$; NRT, 92.1\%; prescription cessation medication, $68.2 \%$. Awareness of cessation aids was lowest among Black Africans, men, and persons with little or no income (table 2).

\section{Differences in cessation behaviours and attitudes by demographic characteristics}

A past quit attempt was reported by $74.6 \%$ of all current combustible smokers (table 2 ). The proportion reporting a past quit attempt was highest and lowest among the following groups (all $\mathrm{p}<0.05)$ : white group $(79.0 \%)$ versus other race $(71.1 \%)$; persons' aged $\geq 66$ years $(82.4 \%)$ versus $18-25$ years $(67.4 \%)$; those earning monthly income of R30 001-50 000 (81.5\%) versus undisclosed income $(68.9 \%)$; and those reporting 'bad' (81.8\%) versus 'very good' health $(65.6 \%)$.

Factors triggering a quit attempt also varied by subgroups (table 3). Men were less likely than women 
Table 1 Ever ${ }^{\star}$ and current† use of tobacco products among South African adults, 2018 ( $\left.n=18208\right)$

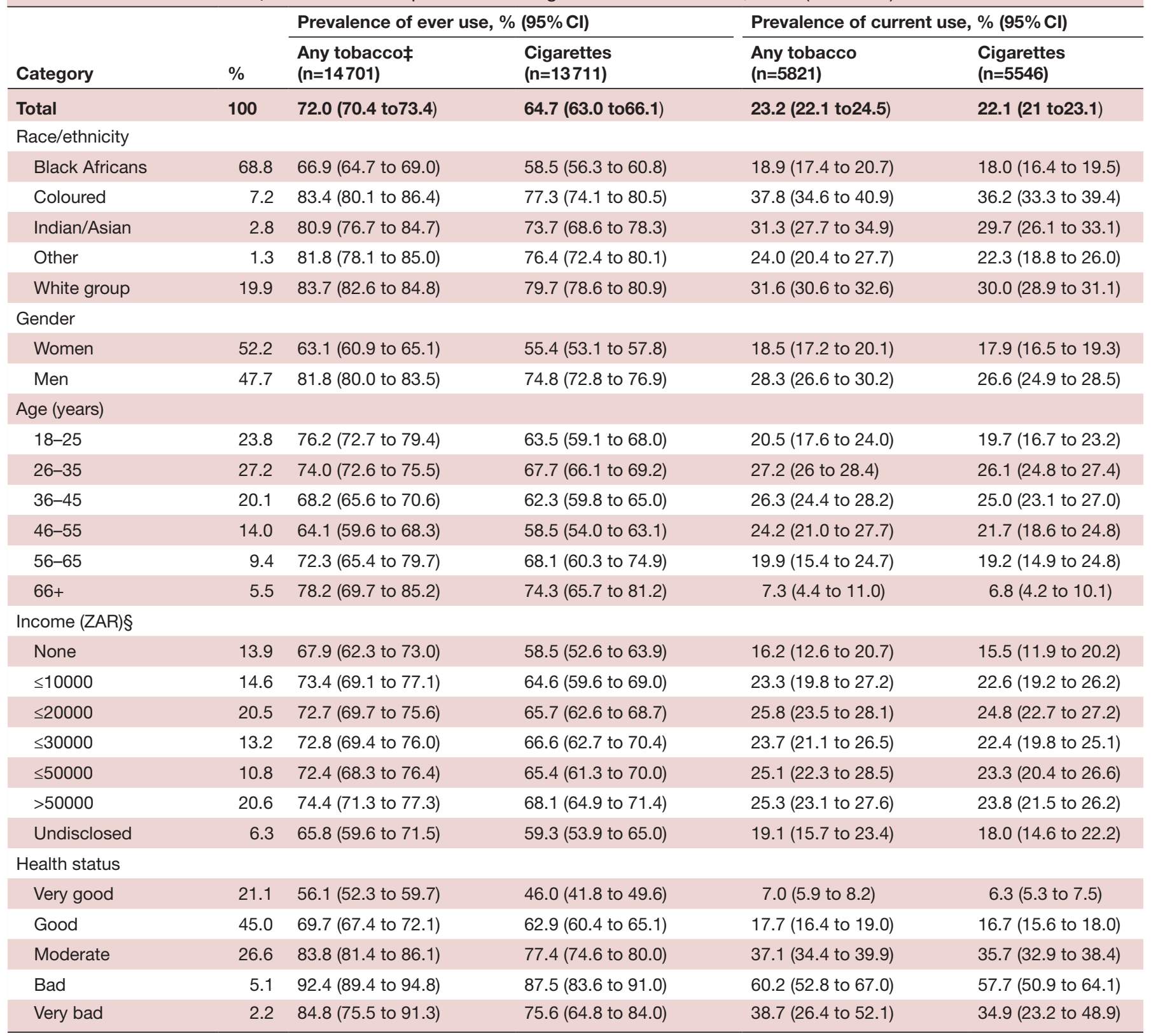

*Ever tobacco product use was defined as having used the specified tobacco product on at least one occasion during lifetime and included those who only experimented, former, occasional and regular users.

†Current tobacco product users were defined as those who self-identified as being a regular user of 'smoke or smokeless' products in general and also reported using the specified product class at any frequency at the time of the survey.

$\ddagger$ Any tobacco product included cigarettes, cigars/pipes/ roll-your-own tobacco, e-cigarettes, and heat-not-burn, or any other 'smoke or smokeless' product.

$\S$ Each income category not inclusive of previous grouping (ie, mutually exclusive).

ZAR, South African rand.

to attempt to quit because of family/partner pressure, including having kids (adjusted OR $(\mathrm{AOR})=0.84)$, but more likely to attempt following advice from a health professional (AOR=1.24); a New Year's Resolution (AOR=1.31); increasing cost of cigarettes (AOR=1.44); a health scare $(A O R=1.61)$ and desire for a healthier lifestyle $(\mathrm{AOR}=1.70)$. Compared with Black Africans, all other race/ethnic groups had lower odds of attempting to quit because of a health scare but were all more likely (except Indians/Asians) to quit because of increasing cost of cigarettes. Interestingly, income status was not independently associated with having made a quit attempt because of increasing cost of cigarettes; it was however associated with attempting to quit on account of advice from a health professional. Smokers with suboptimal self-rated health reported higher odds of attempting to quit following advice from a health professional or after a health scare, compared with those reporting 'very good' health. Compared with those aged 18-25 years, the odds of attempting to quit because of public smoking bans 


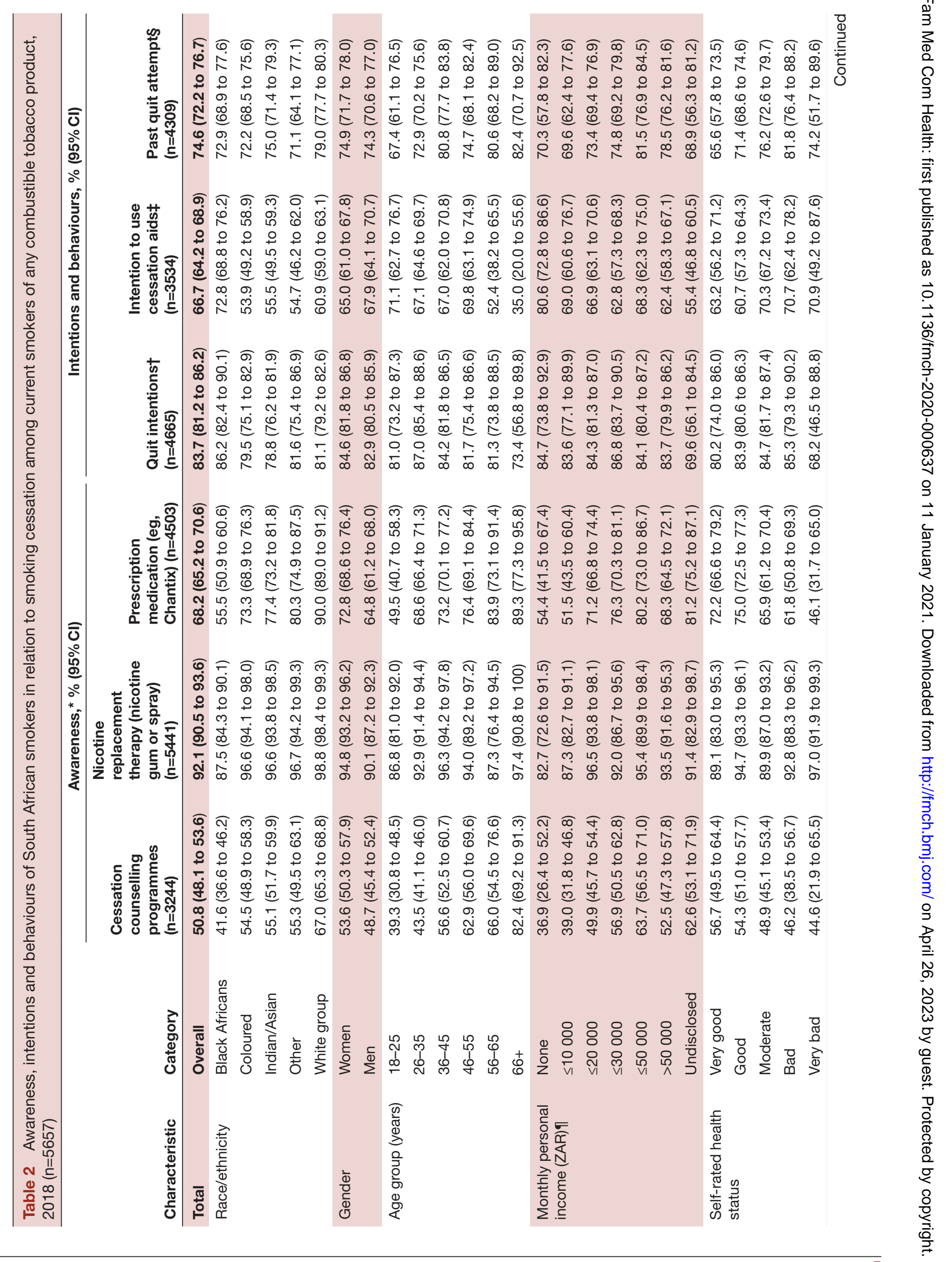




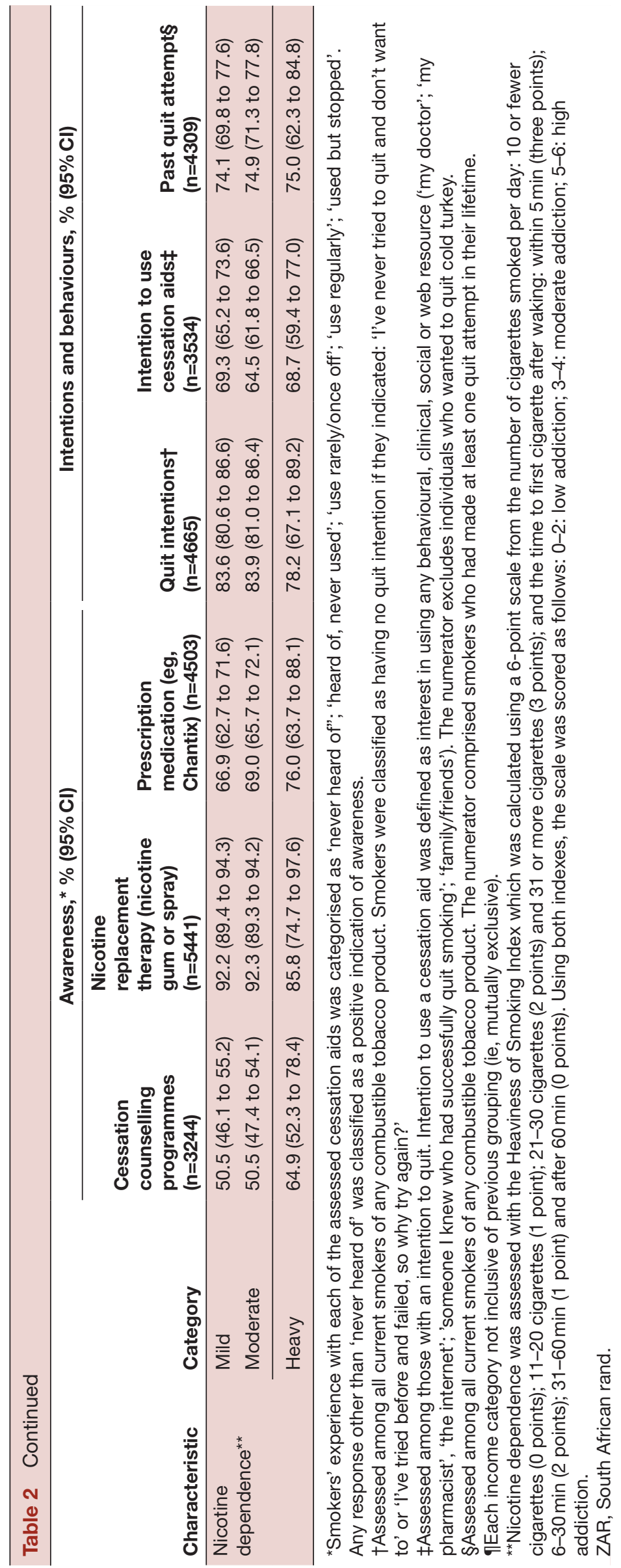




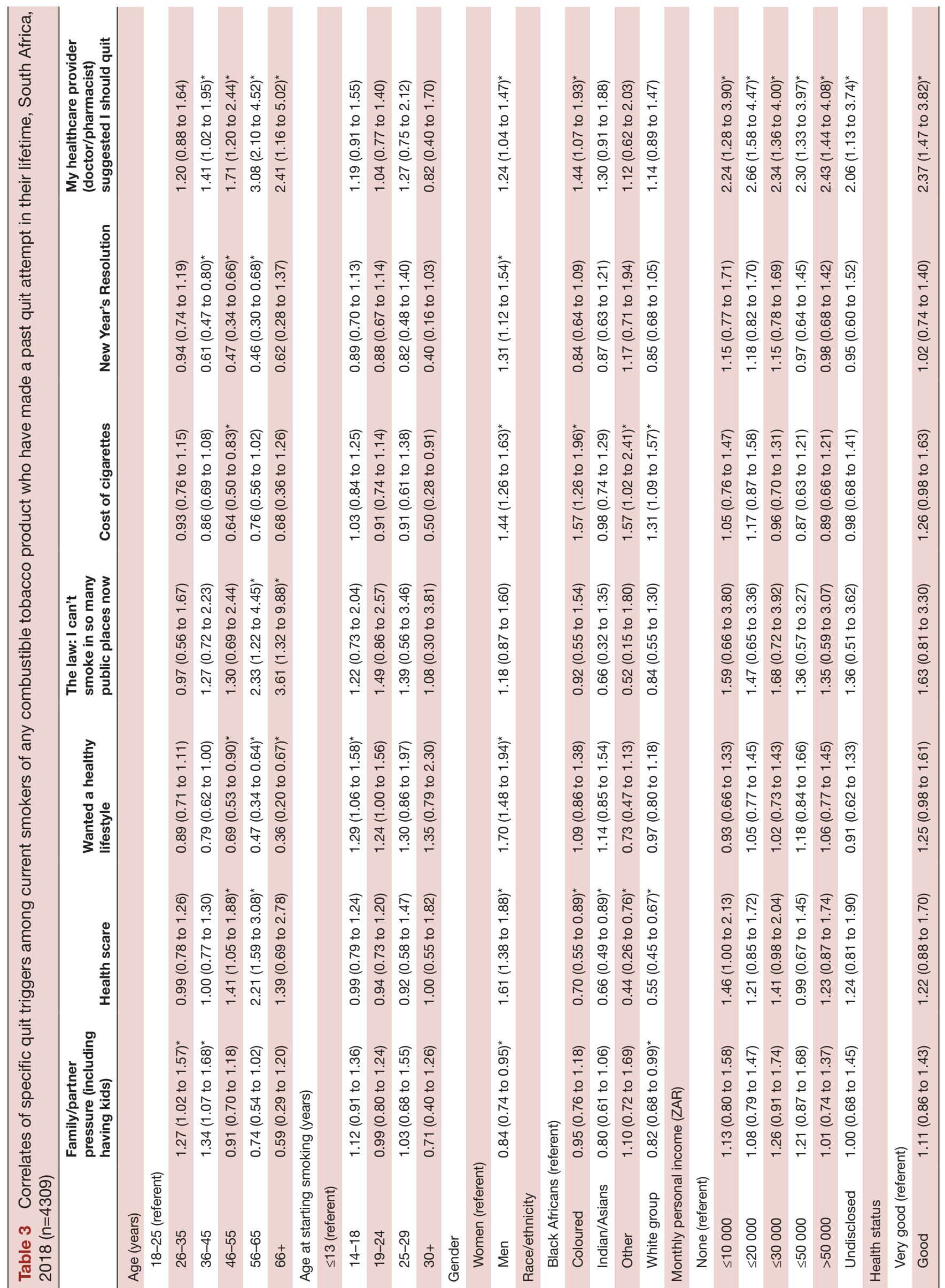


were higher among those aged $56-65$ years $(\mathrm{AOR}=2.33)$ and $\geq 66$ years $(\mathrm{AOR}=3.61) \quad($ all $\mathrm{p}<0.05)$. Older adults aged $56-65$ years were also more likely to attempt to quit after a specific health scare incident $(\mathrm{AOR}=2.21)$, but less likely to attempt out of a general desire to maintain a healthy lifestyle $(\mathrm{AOR}=0.47) \quad($ all $\mathrm{p}<0.05)$.

Use of different cessation aids among current combustible smokers who made a past quit attempt was as follows (table 4): any medication (ever use, $40.0 \%$; current use, $28.0 \%$ ); counselling (ever use, $9.8 \%$; current use, $7.1 \%$ ); any cessation aid, that is, pharmacotherapy and/or counselling (ever use, $42.8 \%$; current use, $31.0 \%$ ). Online supplemental figure 2 shows the prevalence of ever use of different cessation aids among those who quit in the past year. Disparities existed in use of cessation aids among current combustible smokers who made a past quit attempt; current use of any cessation aid among white group $(45.7 \%)$ was almost twofold higher than among Black Africans (24.6\%) or coloured (24.3\%). Similarly, current use of any cessation aid among those earning R30 001-50 000 monthly (46.1\%) was approximately fourfold higher than those with no income $(12.2 \%)$.

Of current combustible smokers intending to quit, $66.7 \%$ indicated interest in using a cessation aid for future quitting and only $33.3 \%$ wanted to quit cold turkey. By specific aids, $24.7 \%$ of those planning to use any cessation aid were interested in getting help from a pharmacist, $44.6 \%$ from a doctor, $49.8 \%$ from someone who had successfully quit, $30.0 \%$ from a family member and $26.5 \%$ from web resources. Past use of any cessation aid was a determinant of planned use $(\mathrm{AOR}=1.67, \mathrm{p}<0.05)$. Demographic variations in planned and past utilisation of cessation aids are highlighted in tables 2 and 4, respectively. Of all current combustible smokers regardless of past quit attempt, $27.1 \%$ reported current use of a smoking cessation aid.

\section{Differences in cessation behaviours and attitudes by psychographic and other tobacco-use characteristics}

Among current combustible smokers who had made a quit attempt, ever e-cigarette users were more likely than never e-cigarette users to have ever used cessation counselling (AOR $=1.92 ; 95 \% \mathrm{CI}=1.55$ to 2.37$)$; NRT (AOR=1.73; 95\% CI=1.50 to 1.99); prescription medication (AOR=1.55; $95 \% \mathrm{CI}=1.33$ to 1.81 ) and any cessation aid (AOR=1.72; 95\% CI=1.50 to 1.97 ), after adjusting for age, gender, race, income and heaviness of smoking. Among current combustible smokers, ever and current e-cigarette users were also more likely to report current use of cessation aids at the time of the survey (table 5). Figure 1 compares the number of different cessation aids ever used of the four specific aids assessed: nicotine patch, nicotine spray, prescription medication and cessation counselling. The results showed that among e-cigarette never users, the percentages that reported ever use of 0 , $1,2,3$ or all 4 cessation aids were $64.1 \%, 23.2 \%, 8.8 \%$, $2.8 \%$ and $1.1 \%$, respectively; the corresponding percentages among e-cigarette ever users were $49.4 \%, 26.3 \%$, 


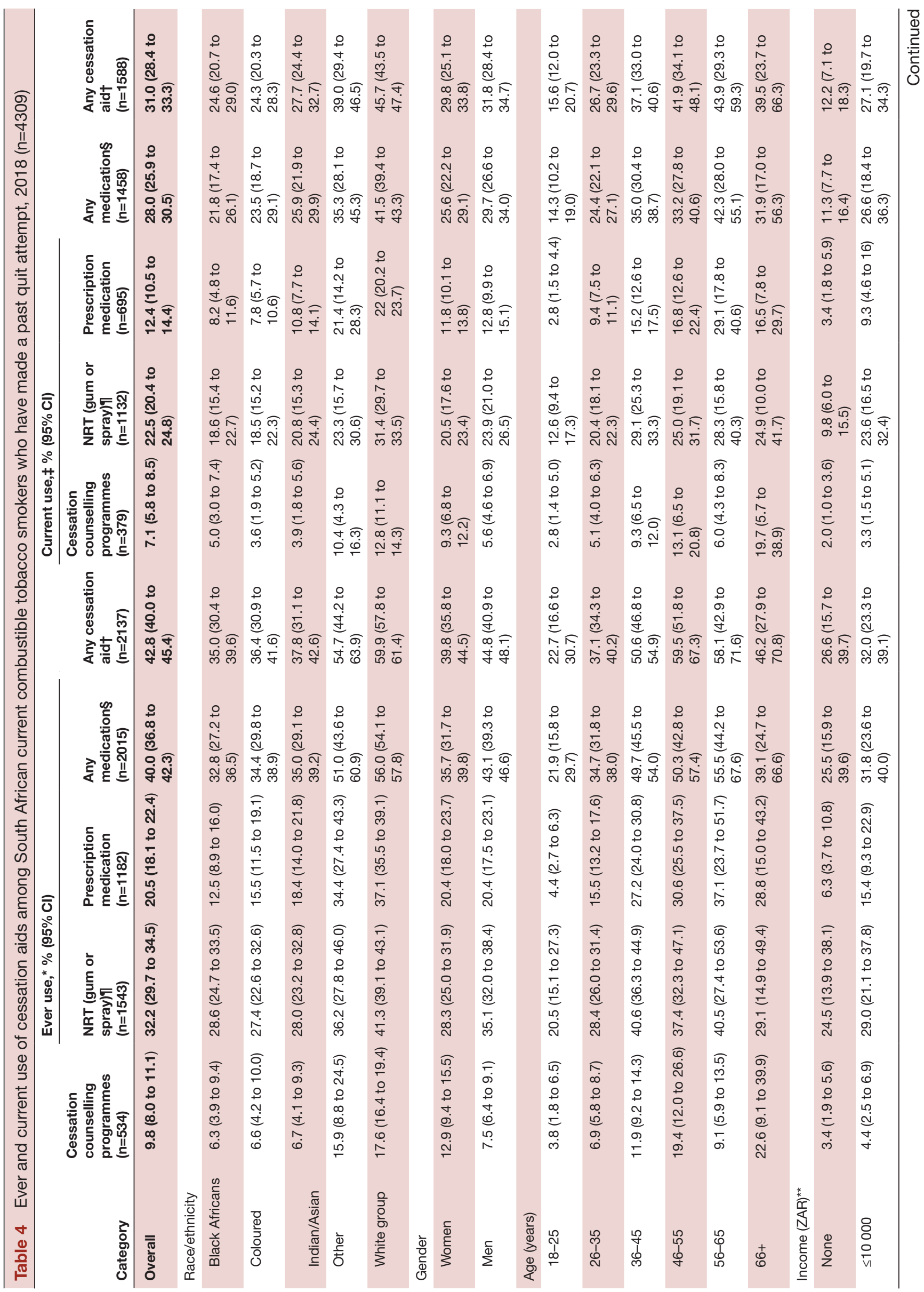




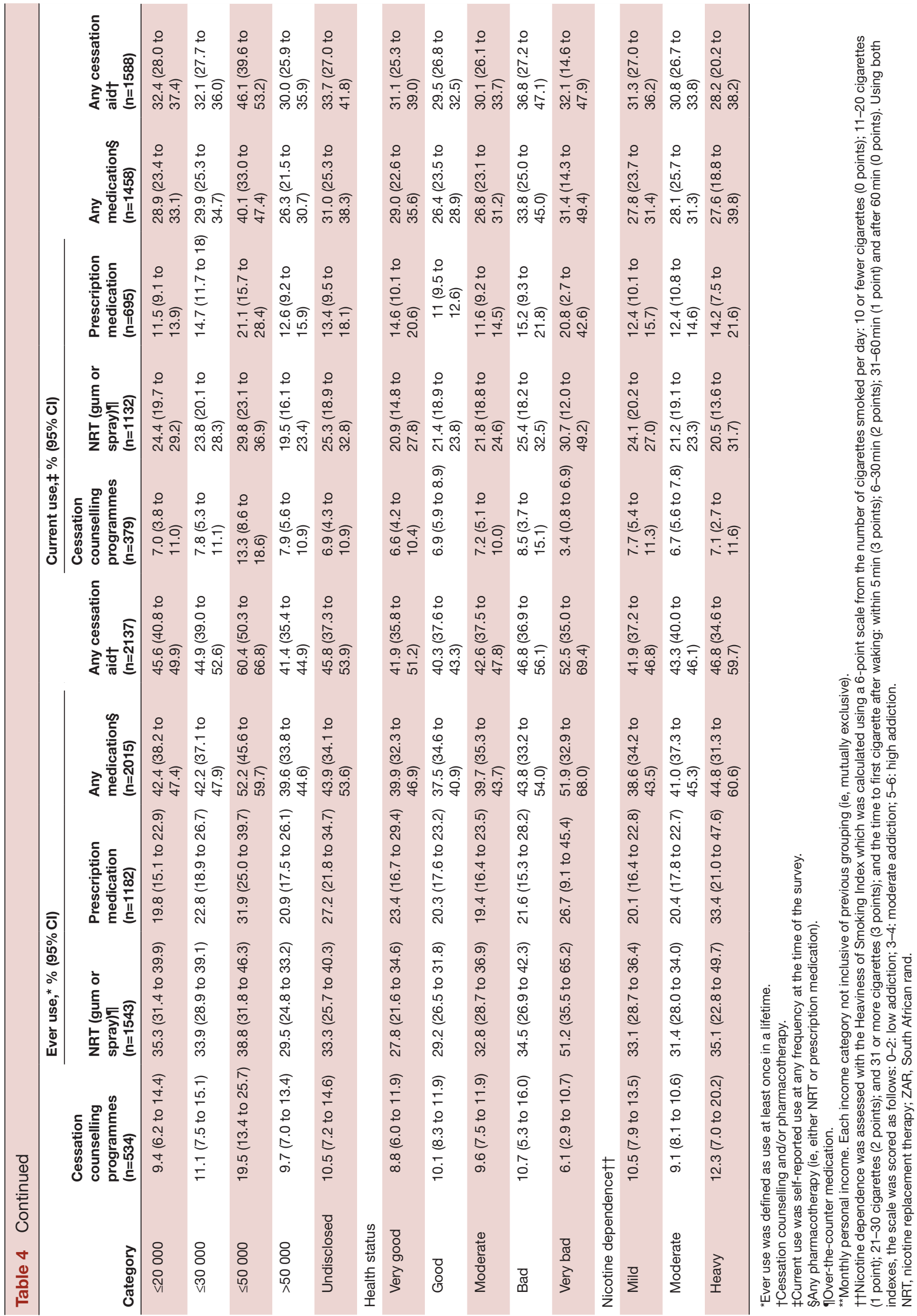




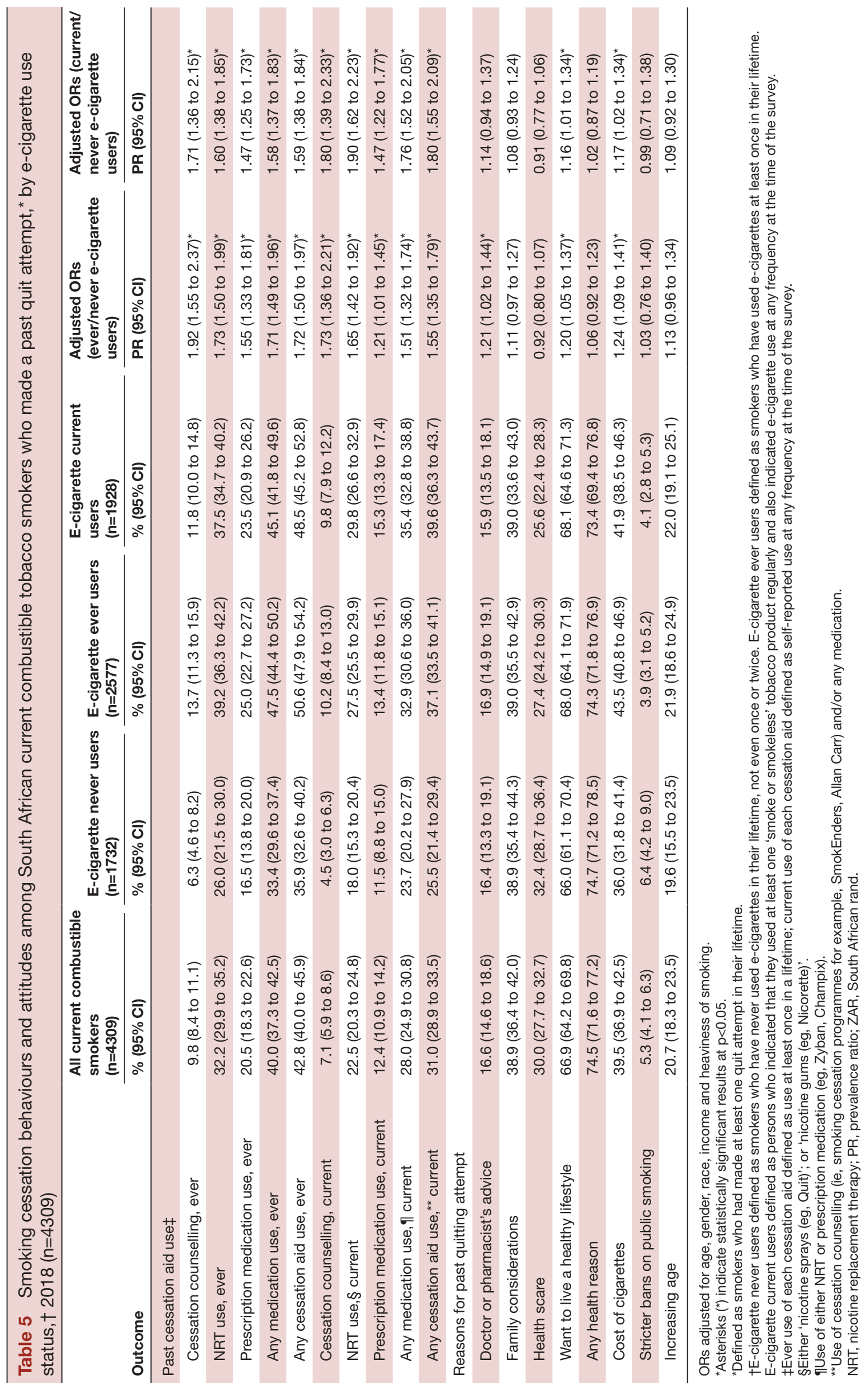




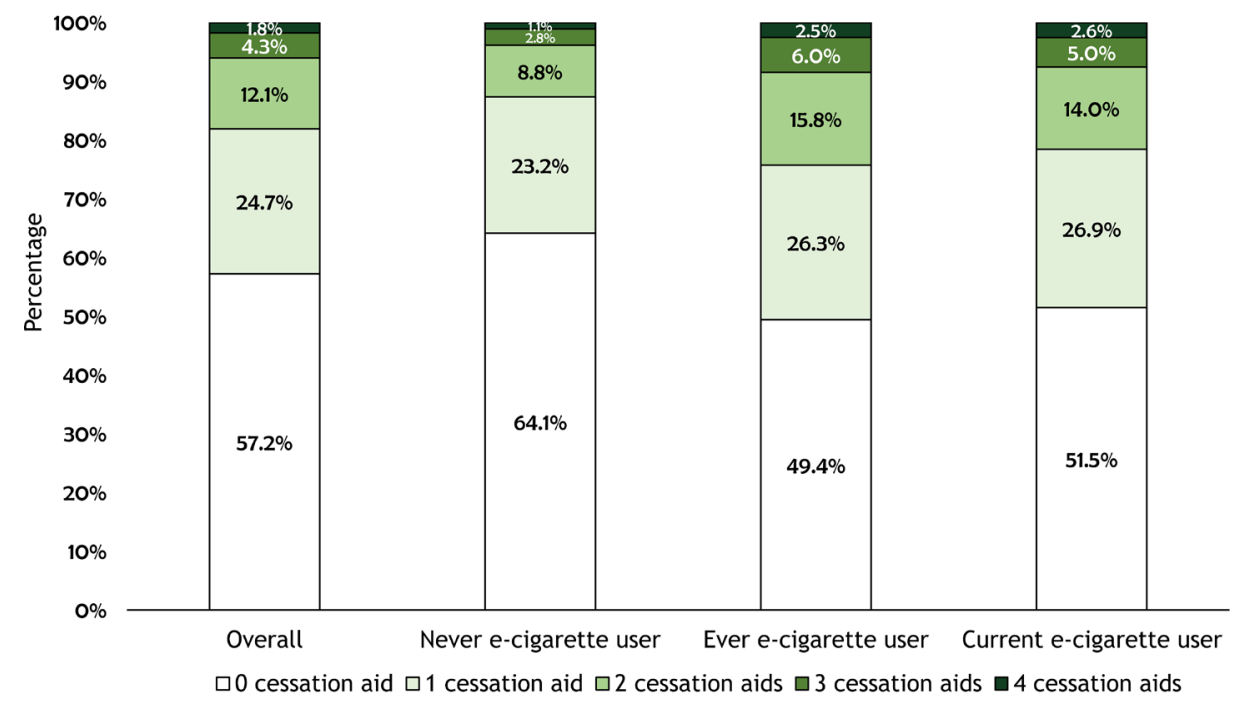

Figure 1 Number of distinct cessation aids ever used by current combustible smokers who had made a quit attempt, overall and by e-cigarette use status. Denominator was smokers who had tried to quit at least once in their lifetime. Ever use of the assessed cessation aids was defined as use of the specified cessation aid at least once in a lifetime. Four distinct cessation aids were assessed including 'nicotine sprays (eg, Quit)'; 'nicotine gums (eg, Nicorette)'; 'pharmaceutical medication to stop smoking (eg, Zyban, Champix)' and 'smoking cessation programmes (eg, SmokEnders, Allan Carr)'. E-cigarette never users defined as smokers who have never used e-cigarettes in their lifetime, not even once or twice. E-cigarette ever users defined as smokers who have used e-cigarettes at least once in their lifetime. E-cigarette current users defined as persons who indicated that they used at least one 'smoke or smokeless' tobacco product regularly and also indicated e-cigarette use at any frequency at the time of the survey.

$15.8 \%, 6.0 \%$ and $2.5 \%(\mathrm{p}<0.05)$. Among all ever e-cigarette users, $43.5 \%$ were current combustible tobacco smokers; of current e-cigarette users, $97.5 \%$ were current combustible tobacco smokers.

Among current combustible smokers, increasing cost of cigarettes predicted an attempt to quit cigarette smoking among e-cigarette ever versus never users $(\mathrm{AOR}=1.24$; $95 \% \mathrm{CI}=1.09$ to 1.41 ). E-cigarette ever users were also more likely to attempt to quit smoking cigarettes because of advice from a doctor or pharmacist (AOR $=1.21 ; 95 \%$ $\mathrm{CI}=1.02$ to 1.44 ).

Among current combustible smokers overall, reasons for smoking predicted quit attempts (figure 2). The odds of making a quit attempt were higher among those who smoked to relieve stress (AOR=1.26); because they thought it was 'cool' $(\mathrm{AOR}=1.30)$ or because of peer pressure $(\mathrm{AOR}=1.35)($ all $\mathrm{p}<0.05)$. Conversely, those who smoked because they enjoyed the smoking experience

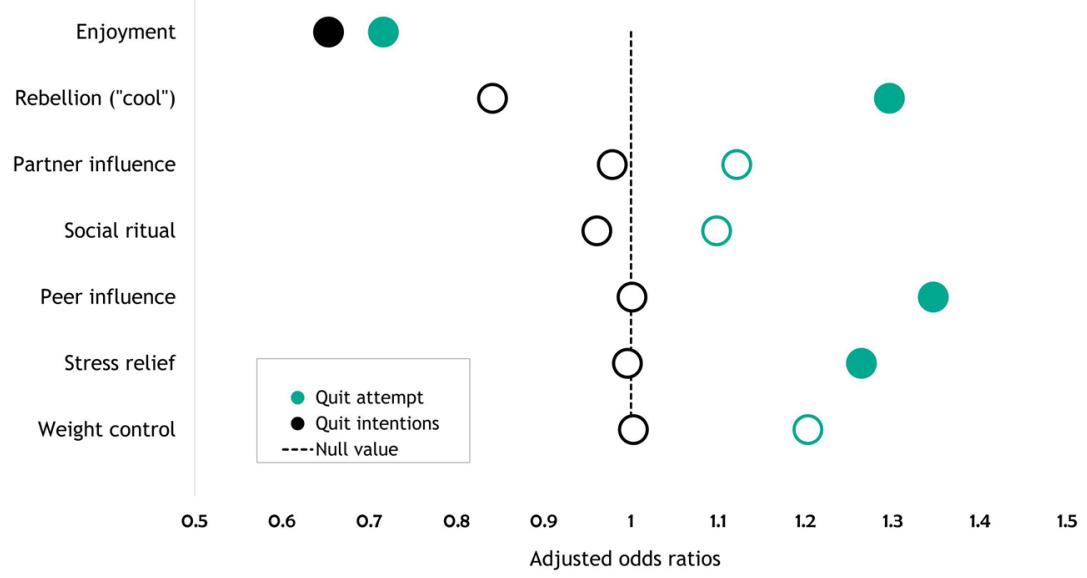

Figure 2 Reason for smoking as a predictor of past quit attempts and future quit intentions among current smokers of combustible tobacco products. Note: solid=statistically significant; hollow=non-significant. ORs were computed adjusting for age, gender, race/ethnicity, income, self-rated health status and nicotine-dependence status. Quit attempters were smokers who had made at least one quit attempt in their lifetime. Smokers were classified as not having a quit intention if they indicated: 'I've never tried to quit and don't want to' or 'I've tried before and failed, so why try again?' 


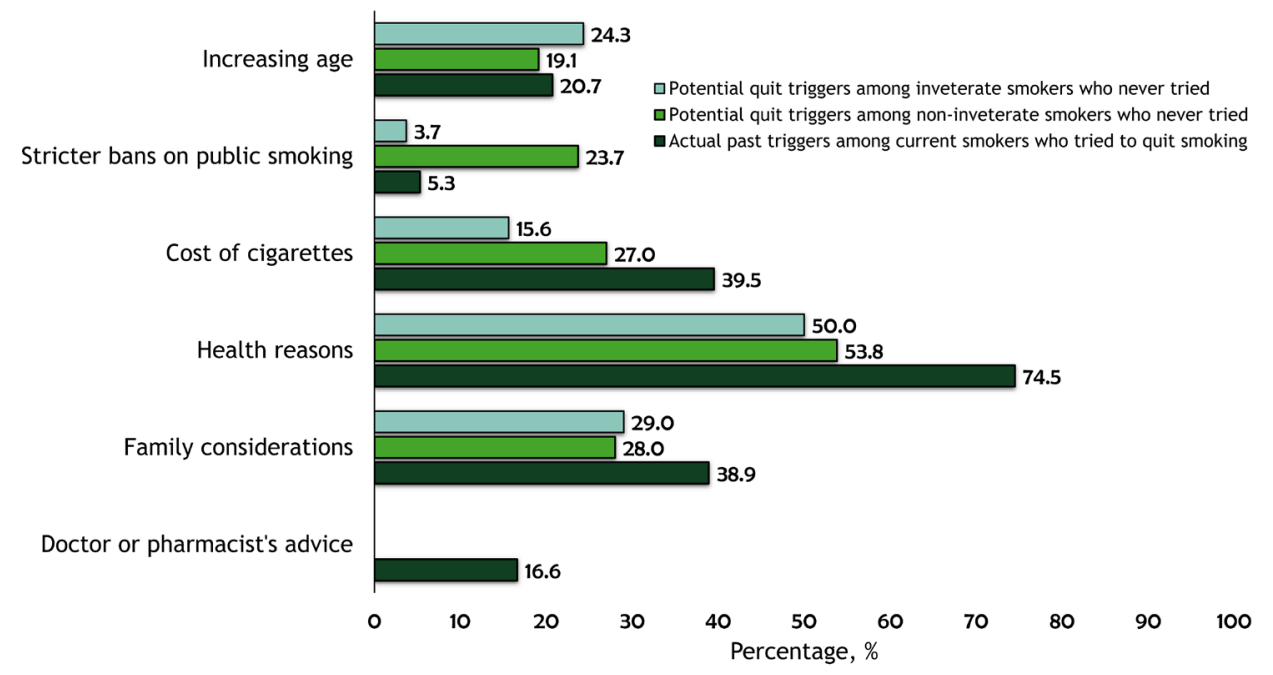

Figure 3 Actual triggers of a past quit attempt among current combustible tobacco smokers who have attempted to quit, as well as potential (perceived) triggers among those who have never tried to quit. Health reasons among those who tried to quit include 'health scare' or 'wanted a healthy lifestyle'. The response options analysed as 'increasing age' were slightly different for ever quit attempters ('New Year's Resolution') versus never quit attempters ('when I am older').

had lower odds of making a quit attempt $(\mathrm{AOR}=0.72)$ or intending to quit smoking (AOR=0.65) (all $\mathrm{p}<0.05)$. Reasons cited for smoking relapse included quitting is hard $(56.9 \%)$, smoking is enjoyable $(34.1 \%)$, low selfefficacy in quitting successfully $(13.8 \%)$ or the perception that smoking is safe $(1.2 \%)$. Similarly, the most commonly cited reason for having never made a quit attempt was that it is too hard to quit $(57.1 \%)$ followed by enjoyment of smoking $(49.2 \%) ; 4.4 \%$ had never attempted to quit because they perceived smoking to be safe.

Among those who had never tried to quit smoking, inveterate smokers-comprising $6.1 \%$ of all current combustible smokers-differed from other nonattempters who otherwise had a quit intention in some respects (figure 3 ). Inveterate smokers were less likely to consider comprehensive smoke-free laws (3.7\% vs $23.7 \%$ ) or increasing cost of cigarettes $(15.6 \%$ vs $27.0 \%)$ as things that could ever make them consider quitting (all $\mathrm{p}<0.05$ ). No significant differences were observed by other factors.

\section{Results of sensitivity analyses}

The indicators compared between the web-based and the household-based surveys of South African adults showed very similar findings within weighted analyses (online supplemental figure 3). For example, current use of any tobacco product was $24.6 \%$ in the 2017 SASAS versus $23.2 \%$ in the web survey. Slightly wider differences were observed in quit attempts $(60.6 \%$ for SASAS vs $74.6 \%$ in the web survey), consistent with differences in case definition (past year quit attempts for SASAS vs lifetime quit attempts in the web survey).

\section{DISCUSSION}

Awareness of cessation aids among current combustible smokers varied by type of cessation aid: smoking cessation programmes, $50.8 \%$; prescription cessation medication, $68.2 \%$ and NRT, $92.1 \%$. Awareness of cessation aids was lowest among Black Africans, men and persons with little or no income. Of all current combustible smokers, $74.6 \%$ had ever attempted to quit and $42.8 \%$ of these quit attempters had ever used any cessation aid. Among past quit attempters, ever e-cigarette users were more likely than never e-cigarette users to have ever used any cessation aid $(50.6 \%$ vs $35.9 \%, \mathrm{p}<0.05)$. Of current combustible smokers intending to quit, $66.7 \%$ indicated interest in using a cessation aid for future quitting and only $33.3 \%$ wanted to quit cold turkey.

Despite high awareness of cessation aids among South African smokers, utilisation was low. Awareness and use were much lower for cessation counselling programmes and for prescription medications compared with NRT, possibly because of the ubiquitous display of NRT at retail outlets. Most NRT formulations, including oral spray and inhaler, can be purchased in South Africa as over-the-counter medication within pharmacies, supermarkets or online. However, as our findings revealed, lowincome smokers may face severe limitations in accessing these medications. A complete regimen of nicotine patch lasting up to 12 weeks long, one patch per day, for a heavy smoker (10+ cigarettes), could cost between R9070 (\$605) and R21 580 (\$1438), based on current retail prices in South Africa and recommended usage. ${ }^{15}$ Including drugs for nicotine-dependence treatment on the South African Essential Drugs list, ${ }^{13} 14$ and expanding coverage for smoking cessation treatment within the National Health Insurance ${ }^{19}$ may increase access and utilisation of evidence-based cessation aids among South African smokers.

Current utilisation rates for cessation aids in our study were very similar to those reported in the USA, including 
for cessation counselling $(7.1 \%$ vs $6.8 \%)$, any medication use $(28.0 \%$ vs $29.0 \%)$ and use of any cessation aid $(31.0 \%$ vs $31.2 \%$, South Africa vs the USA, respectively). ${ }^{20}$ The pattern of disparities in access and use of cessation aids by socioeconomic status is also consistent with those reported elsewhere. ${ }^{621}$ In our study, Black Africans reported greater interest in using cessation aids and higher intentions to quit, but reported lower past use of cessation aids, suggesting that the gap in utilisation of cessation aids is largely driven by differences in socioeconomic status, rather than differences in interest or motivation. Increasing delivery of brief cessation counselling within all clinical settings (including public health facilities that serve low-income groups), as called for in Article 14 of the WHO Framework Convention on Tobacco Control, ${ }^{22}$ can help smokers quit and improve their health. ${ }^{23}{ }^{24}$ In addition, enhancing the effectiveness of clinical smoking cessation services (eg, the 5As) can help increase cessation. For example, our findings suggest that asking smokers the reason why they smoke could be potentially useful in assessing their willingness to quit. Certain life-changing moments, such as the diagnosis of a serious condition associated with, or exacerbated by smoking (eg, chronic obstructive pulmonary disease) can be leveraged to provide counselling and motivate quitting. ${ }^{25}$ Our results showed that a health scare was associated with quitting, especially among those with poor health conditions. Notably, older adults were less likely to make a quit attempt just for maintaining a healthy lifestyle but were more likely to do so on account of a health scare.

South Africa has not officially adopted tobacco harm reduction, however, some in the public health community have argued for the effectiveness of this strategy among 'inveterate' smokers who are unwilling or unable to quit. ${ }^{26}$ The potential viability of a harm reduction approach, from a public health context, however rests on assumptions that: (1) there is a large pool of inveterate smokers; (2) that these smokers will be interested in switching to, and exclusively using 'reduced-risk' products which would help them quit; and (3) that a regulated climate exists to prevent unwanted consequences among youth. Our findings however disprove several of these assumptions within the South African context. Only about $6 \%$ of current combustible smokers were considered 'inveterate', and even these were open to quitting for health reasons $(50 \%)$, family considerations (29\%), increasing age $(24 \%)$ and increasing costs of cigarettes $(15.6 \%)$.

As the tobacco market and regulatory landscapes in South Africa continue to evolve rapidly, regulation of novel products is critical to minimise potential population-level harms, including relapse and perpetuation of smoking behaviour among smokers. Deeming and regulating e-cigarettes as tobacco products under the proposed legislation may benefit public health, ${ }^{11} 27$ not only in South Africa, but regionally as well, given the leadership role South Africa plays in the region. These findings can help inform comprehensive tobacco prevention and control efforts, including restricting unsubstantiated marketing claims of e-cigarettes as effective smoking cessation aids within South Africa.

Socioeconomic status was not a significant predictor of quitting on account of 'increasing cigarette cost', possibly because of the use of price-minimising strategies by smokers, including buying cheap brands, single sticks or switching to cheaper RYO cigarettes. ${ }^{28}{ }^{29}$ Policies that address cross-product price inequalities can help reduce demand and use of tobacco products. ${ }^{30}$ We also found that older adults, who had the lowest smoking prevalence, were the only demographic group to attempt to quit smoking in response to public bans on smoking, suggesting limited compliance. Stronger enforcement of policies that prohibit smoking in public places may prevent relapse by reducing social cues and denormalising smoking. ${ }^{31} 32$

More robust epidemiological studies that address threats to internal validity are needed to test some of the hypothesis generated from our study. For example, our results suggested that claims of e-cigarettes being effective cessation aids may be probably overstated in the South African context, given the observation that smokers who used e-cigarettes were more likely than non-e-cigarette users to have used other cessation aids. Clinical or realworld effectiveness trials are needed to evaluate the independent effect of e-cigarettes on smoking cessation in South Africa.

This study is not without limitations. First, it is impossible to determine temporality with the cross-sectional design (eg, order of using e-cigarettes and evidence-based cessation aids). Second, triggers of past quit attempt could have varied for individuals with multiple quit attempts as could also the types of cessation aids used. Third, the selfreported measures are subject to misreporting. Finally, despite the use of calibration weights, the weighted sample may still not be entirely representative of the South African adult population because adjustments were only made for a few variables for which information was available in the dataset. We however found that comparison of results with 2017 SASAS, a household-based survey, yielded similar results on assessed indicators.

\section{CONCLUSION}

Most smokers were interested in quitting, but only about one-third of smokers who had tried to quit had ever used any cessation aid; NRT was the most used cessation aid. Disparities existed in the use of any cessation aid, with utilisation being least among Black Africans and individuals of low socioeconomic position. Smokers who tried to quit and used e-cigarettes reported higher use of pharmacological cessation aids and counselling than non-e-cigarette users. Intensified implementation of comprehensive tobacco prevention and control strategies that include barrier-free access to cessation aids, price increases on tobacco products, comprehensive 
smoke-free laws and mass media educational campaigns that warn of the dangers of tobacco use may accelerate cessation rates among South African adults.

Contributors IA conceptualised and designed the study and drafted the initial manuscript. CE and $\mathrm{OA}-\mathrm{Y}$ helped conceptualise the study and critically reviewed and revised the manuscript. All authors approved the final manuscript as submitted and agree to be accountable for all aspects of the work.

Funding The African Capacity Building Foundation Grant number 333.

Competing interests None declared.

Patient consent for publication Not required.

Ethics approval The study was approved by the University of Pretoria's Faculty of Health Sciences' Ethics Review (no. 39/2019).

Provenance and peer review Not commissioned; externally peer reviewed.

Data availability statement Requests for data should be sent to the corresponding author and will be considered on a case-by-case basis.

Supplemental material This content has been supplied by the author(s). It has not been vetted by BMJ Publishing Group Limited (BMJ) and may not have been peer-reviewed. Any opinions or recommendations discussed are solely those of the author(s) and are not endorsed by BMJ. BMJ disclaims all liability and responsibility arising from any reliance placed on the content. Where the content includes any translated material, BMJ does not warrant the accuracy and reliability of the translations (including but not limited to local regulations, clinical guidelines, terminology, drug names and drug dosages), and is not responsible for any error and/or omissions arising from translation and adaptation or otherwise.

Open access This is an open access article distributed in accordance with the Creative Commons Attribution Non Commercial (CC BY-NC 4.0) license, which permits others to distribute, remix, adapt, build upon this work non-commercially, and license their derivative works on different terms, provided the original work is properly cited, appropriate credit is given, any changes made indicated, and the use is non-commercial. See: http://creativecommons.org/licenses/by-nc/4.0/.

\section{REFERENCES}

1 Euromonitor International. Passport. cigarettes in South Africa, 2016.

2 Statistics South Africa. What are South Africans dying of? Available: http://www.statssa.gov.za/?p=1023 [Accessed 02 Feb 2019].

3 Sitas F, Urban M, Bradshaw D, et al. Tobacco attributable deaths in South Africa. Tob Control 2004;13:396-9.

4 National Center for Chronic Disease Prevention and Health Promotion, Office on Smoking and Health. The health consequences of Smoking-50 years of progress: a report of the surgeon General. Atlanta (GA): Centers for Disease Control and Prevention, 2014.

5 National Center for Chronic Disease Prevention and Health Promotion (US), Office on Smoking and Health. Office on smoking and health. How tobacco smoke causes disease: the biology and behavioral basis for Smoking-Attributable disease: a report of the surgeon General. Atlanta (GA): Centers for Disease Control and Prevention, 2010.

6 Ayo-Yusuf OA, Szymanski B. Factors associated with smoking cessation in South Africa. S Afr Med J 2010;100:175-9.

7 National Council Against Smoking. Need help to stop smoking? call our quit line 011720 3145. Available: https://www.againstsmoking. co.za/ [Accessed 02 Aug 2019].

8 Reddy P, Zuma K, Shisana O, et al. Prevalence of tobacco use among adults in South Africa: results from the first South African National health and nutrition examination survey. S Afr Med J 2015;105:648-55.

9 Malan M, Leaver R. Political change in South Africa: new tobacco control and public health policies, 2011.

10 Government Gazette. Tobacco products Amendment act, 1999 regulations, regulation Gazette No. 6689. 414, 1999.

11 Tobacco Control Laws. Legislation by country: South Africa. obtained on January 2, 2018, 2017. Available: https://www. tobaccocontrollaws.org/legislation/country/south-africa/laws
12 Sanni S, Hongoro C, Ndinda C, et al. Assessment of the multisectoral approach to tobacco control policies in South Africa and Togo. BMC Public Health 2018;18:962.

13 World Health Organization. Essential medicines selection. South Africa. Available: https://www.who.int/selection_medicines/country_ lists/zaf_phc_2008.pdf?ua=1 [Accessed 16 Jul 2020].

14 National Department of Health. Standard treatment guidelines and essential medicines list for South Africa, 2017. Available: http://www. health.gov.za/index.php/standard-treatment-guidelinesand-essentialmedicines-list [Accessed 02 Sep 2019].

15 Johnson \& Johnson. Nicorette®. Available: https://www.jnjconsumer. co.za/our-brands/nicorette [Accessed 16 Jul 2020].

16 Laranjo L. Social media and health behavior change. participatory health through social media. Elsevier, 2016: 83-111.

17 Prochaska JO, DiClemente CC. Stages and processes of self-change of smoking: toward an integrative model of change. J Consult Clin Psychol 1983;51:390-5.

18 Agency for Healthcare Research and Quality. Treating tobacco use and dependence: 2008 update. content last reviewed February 2020. agency for healthcare research and quality, Rockville, MD. Available: https://www.ahrq.gov/prevention/guidelines/tobacco/index.htm [Accessed 16 Oct 2020].

19 South African Government. National health insurance. Available: https://www.gov.za/about-government/government-programmes/ national-health-insurance-0 [Accessed 02 Sep 2019].

20 Babb S, Malarcher A, Schauer G, et al. Quitting smoking among adults - United States, 2000-2015. MMWR Morb Mortal Wkly Rep 2017;65:1457-64.

21 Babb S, Malarcher A, Asman K, et al. Disparities in cessation behaviors between Hispanic and non-Hispanic white adult cigarette smokers in the United States, 2000-2015. Prev Chronic Dis 2020;17:E10.

22 World Health Organization. WHO framework convention on tobacco control. Available: https://www.who.int/tobacco/framework/WHO FCTC_english.pdf [Accessed 02 Aug 2019].

23 U.S. Preventive Services Task Force (2015). Final recommendation statement. tobacco smoking cessation in adults, including pregnant women: behavioral and pharmacotherapy interventions. Available: https://www.uspreventiveservicestaskforce.org/Page/Document/ RecommendationStatementFinal/tobacco-use-in-adults-andpregnant-women-counseling-and-interventions1 [Accessed $02 \mathrm{Sep}$ 2019].

24 U.S. Department of Health and Human Services. The health benefits of smoking cessation: a report of the surgeon General. US Department of Health and Human Services, Centers for Disease Control and Prevention, 1990.

25 Kotz D, Huibers MJH, West RJ, et al. What mediates the effect of confrontational counselling on smoking cessation in smokers with COPD? Patient Educ Couns 2009;76:16-24.

26 Polosa R, Morjaria JB, Caponnetto P, et al. Effectiveness and tolerability of electronic cigarette in real-life: a 24-month prospective observational study. Intern Emerg Med 2014;9:537-46.

27 Government Gazette. Department of health (2018). invitation for public Comment on the draft control of tobacco products and electronic delivery systems bill, 2018. Available: https://www.gov. za/sites/default/files/gcis_document/201805/41617gon475re.pdf [Accessed 02 Sep 2019].

28 Africa Tobacco Control Alliance. Sale of single sticks of cigarettes in Africa. survey report from 10 capital cities. Available: https:// atca-africa.org/images/pdf/Atca-single-sticks/Report-Sale-of-SingleSticks-in-Africa.pdf [Accessed 02 Sep 2019].

29 Ayo-Yusuf OA, Olutola BG. 'Roll-your-own' cigarette smoking in South Africa between 2007 and 2010. BMC Public Health 2013;13:597.

30 Agaku IT, Odani S, Armour B, et al. Differences in price of flavoured and non-flavoured tobacco products sold in the USA, 2011-2016. Tob Control 2019:tobaccocontrol-2019-055111.

31 Agaku IT, Perks SN, Odani S, et al. Associations between public e-cigarette use and tobacco-related social norms among youth. Tob Control 2020;29:332-40.

32 Vardavas $\mathrm{Cl}$, Agaku I, Patelarou E, et al. Ashtrays and signage as determinants of a smoke-free legislation's success. PLoS One 2013;8:e72945. 